\title{
Carbazole degradation in the soil microcosm by tropical bacterial strains
}

\author{
Lateef B. Salam, Matthew O. Ilori, Olukayode O. Amund \\ Department of Microbiology, University of Lagos, Lagos, Nigeria.
}

Submitted: July 21, 2014; Approved: November 16, 2014.

\begin{abstract}
In a previous study, three bacterial strains isolated from tropical hydrocarbon-contaminated soils and phylogenetically identified as Achromobacter sp. strain SL1, Pseudomonas sp. strain SL4 and Microbacterium esteraromaticum strain SL6 displayed angular dioxygenation and mineralization of carbazole in batch cultures. In this study, the ability of these isolates to survive and enhance carbazole degradation in soil were tested in field-moist microcosms. Strain SL4 had the highest survival rate $\left(1.8 \times 10^{7} \mathrm{cfu} / \mathrm{g}\right)$ after 30 days of incubation in sterilized soil, while there was a decrease in population density in native (unsterilized) soil when compared with the initial population. Gas chromatographic analysis after 30 days of incubation showed that in sterilized soil amended with carbazole $(100 \mathrm{mg} / \mathrm{kg}), 66.96,82.15$ and $68.54 \%$ were degraded by strains SL1, SL4 and SL6, respectively, with rates of degradation of $0.093,0.114$ and $0.095 \mathrm{mg} \mathrm{kg}^{-1} \mathrm{~h}^{-1}$. The combination of the three isolates as inoculum in sterilized soil degraded $87.13 \%$ carbazole at a rate of $0.121 \mathrm{mg} \mathrm{kg}^{-1} \mathrm{~h}^{-1}$. In native soil amended with carbazole $(100 \mathrm{mg} / \mathrm{kg}), 91.64,87.29$ and $89.13 \%$ were degraded by strains SL1, SL4 and SL6 after 30 days of incubation, with rates of degradation of $0.127,0.121$ and $0.124 \mathrm{mg} \mathrm{kg}^{-1} \mathrm{~h}^{-1}$, respectively. This study successfully established the survivability $\left(>10^{6} \mathrm{cfu} / \mathrm{g}\right.$ detected after 30 days) and carbazole-degrading ability of these bacterial strains in soil, and highlights the potential of these isolates as seed for the bioremediation of carbazole-impacted environments.
\end{abstract}

Key words: bioaugmentation, biodegradation, microcosm, Pseudomonas, Microbacterium, Achromobacter, carbazole.

\section{Introduction}

Bioremediation is the exploitation of the biodegradative activities of microorganisms to remove environmental pollutants and recalcitrant xenobiotics (Habe et al., 2001). Rapid industrialization in agriculture, expansion in the chemical industry and the need to generate cheap forms of energy to drive domestic and industrial activities have resulted in an ever-increasing reliance on anthropogenic organic chemicals, with its attendant contamination of a significant number of soil environments (Reid et al., 2000).

Bioaugmentation is the introduction of strains with desired degradative capabilities against target pollutants, either with or without nutrients, into the contaminated environment to augment the indigenous microbial population (Andreoni and Gianfreda, 2007). Under certain situations, bioaugmentation may be necessary when pollutant-degrading microorganisms are not present at a contaminated site, or where autochthonous degraders cannot rapidly and effi- ciently degrade recalcitrant compounds (Watanabe et al., 1998; Widada et al., 2002). However, mixed outcomes have been reported from studies utilizing such isolates for bioaugmentation (Vinas et al., 2005; Obayori et al., 2013). This is attributed partly to unfavorable interactions between the introduced organisms and the autochthonous populations and poor adaptations to environmental conditions in the field (Johnsen et al., 2005).

Soil microcosm studies in the laboratory permit the selection of suitable microorganisms that can survive for a longer period when introduced into polluted sites and that possess a high catabolic activity with which to degrade pollutants. Laboratory studies also allow for the manipulation of various environmental factors and growth conditions that could favor the optimal activity of degradative microorganisms and facilitate effective biodegradation and bioremediation of polluted soils. The results obtained from such studies will be useful in designing novel bioreme- 
diation strategies that may be necessary to reclaim polluted soil in field conditions.

Carbazole $\left(\mathrm{C}_{12} \mathrm{H}_{9} \mathrm{~N}\right.$, dibenzopyrrole diphenylenimine, CAS no. 86-74-8) is a non-basic tricyclic aromatic N-heteroatomic compound. It has a molecular weight of $167.21 \mathrm{~g} / \mathrm{mol}$, boiling and melting points of $355^{\circ} \mathrm{C}$ and $246^{\circ} \mathrm{C}$, a water solubility of $1.2 \mathrm{mg} / \mathrm{L}$, a vapor pressure of $1 \times 10^{-4} \mathrm{~Pa}$ and an octanol/water partition coefficient (log $\mathrm{K}_{\mathrm{ow}}$ ) of 3.72 (Johansen et al., 1997; Lide, 2003; Blum et al., 2011; Peddinghaus et al., 2012). It is one of the major $\mathrm{N}$-heterocyclic aromatic hydrocarbons in fossil fuels (coal, crude oil, oil derived from oil shale pyrolysis) and is also found in cigarette smoke and from coal and wood combustion. Its release into the environment from diverse anthropogenic sources is of serious health and environmental concern, as carbazole is both mutagenic and toxic and is classified as a "benign tumorigen" (Smith and Hansch, 2000; Nojiri and Omori, 2007). In the literature, only one report details carbazole degradation in the soil by allochthonous microorganisms. Widada et al. (2002) reported the proliferation and survival of marked strain CA10 cells in soil microcosms supplemented with $100 \mu \mathrm{g} / \mathrm{kg}$ of carbazole. At a soil $\mathrm{pH}$ of 6 with little organic matter, the population of marked CA10 rapidly decreased, while at a soil $\mathrm{pH}$ of 7.3 and $2.5 \%$ organic matter, a high cell density was maintained up to 21 days after inoculation, and complete biodegradation of carbazole was shortened from 21 to 7 days.

Previously, we reported three bacterial strains isolated from tropical hydrocarbon-contaminated soils. These strains were phylogenetically identified as Achromobacter sp. strain SL1, Pseudomonas sp. strain SL4 and $M$. esteraromaticum strain SL6 and were shown to mineralize carbazole in batch cultures (Salam et al., 2014; Figure 1). In this study, we evaluate the ability of these isolates to survive and degrade carbazole in the soil individually and as a consortium.

\section{Materials and Methods}

Microorganisms, culture conditions, and inoculant preparation

The isolation and characterization of the bacterial strains used in this study (Achromobacter sp. strain SL1
(AB646575.2), Pseudomonas sp. strain SL4 (AB646578.2) and M. esteraromaticum strain SL6 (AB646579.2)) have been described elsewhere (Salam et al., 2014). The isolates were maintained in glycerol Luria Bertani (LB) broth (1:1) at $-20^{\circ} \mathrm{C}$. Colonies growing on LB agar with a very low percentage of carbazole $(0.005 \%)$ were harvested with a sterile inoculating loop, pooled and transferred to screwcapped bottles containing $5 \mathrm{~mL}$ physiological saline $(0.85 \% \mathrm{NaCl})$. Sufficient culture was transferred to achieve an $\mathrm{OD}_{600}$ of approximately 1.5 .

The inocula were added to a carbon-free mineral medium (CFMM) (Habe et al., 2002) with carbazole $\left(100 \mathrm{mg} \mathrm{L}^{-1}\right)$ in $250 \mathrm{~mL}$ flasks and incubated at room temperature. The cells were harvested at the logarithmic phase of growth by centrifugation. The cell pellets were then washed twice with decreasing concentrations of CFMM and twice with sterile distilled water. Inoculation was carried out after the resuspension of cell pellets in $2.5 \mathrm{~mL}$ of sterile distilled water.

\section{Soil used in this study}

Soil samples were obtained from a vegetable garden in uncontaminated farmland site near Lagos State University, Ojo. Soil samples were taken at a depth of $10-12 \mathrm{~cm}$ using a sterile hand trowel after removing the debris from the soil surface. Samples were collected in clean black polythene bags for physicochemical analysis, while samples were collected in sterile screw-capped bottles for microbiological analysis. Immediate analysis of the samples was carried out within $5 \mathrm{~h}$ of collection, or the samples were stored at $4{ }^{\circ} \mathrm{C}$. Soil physicochemical parameters were determined as described previously (Salam et al., 2014). The water-holding capacity of the soil was determined using a modified container capacity method (Jones et al., 2008). Particle-size analyses were obtained by the Bouyoucous hydrometer method, as modified by Day (1965).

\section{Degradation of carbazole in the soil microcosm}

The degradation of carbazole in the soil microcosm was assessed using a method modified from Kästner et al. (1998). Four different experimental conditions were used: sterilized soil with carbazole $(\mathrm{SSC}=$ sterilized soil + carbazole); unsterilized (native) soil with carbazole ( $\mathrm{NSC}=$ native soil + carbazole); sterilized soil with carbazole and

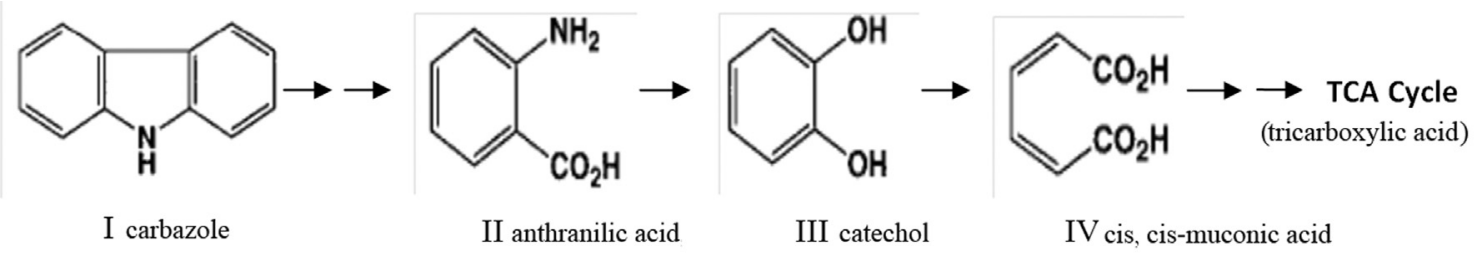

Figure 1 - Simplified degradation pathway of carbazole in Achromobacter sp. strain SL1, Pseudomonas sp. strain SL4 and M. esteraromaticum strain SL6. Only the metabolites identified are shown. Compounds: I, carbazole; II, anthranilic acid; III, catechol; IV, cis, cis-muconic acid; TCA, tricarboxylic acid. 
isolate $(\mathrm{SSC} 1=$ sterilized soil + carbazole + Achromobacter sp. strain SL1; SSC4 $=$ sterilized soil + carbazole + Pseudomonas sp. strain SL4; SSC6 = sterilized soil + carbazole + M. esteraromaticum strain SL6; SSC146 = sterilized soil + carbazole + strains SLI, SL4, SL6); and native soil with carbazole and isolate $(\mathrm{NSC1}=$ native soil + carbazole + strain SL1; NSC4 = native soil + carbazole + strain SL4; NSC6 = native soil + carbazole + strain SL6). Each experimental set-up consisted of a $500 \mathrm{~mL}$ metal cup containing $1 \mathrm{~kg}$ of soil. The soil was sterilized by autoclaving for $30 \mathrm{~min}$, followed by three consecutive $24 \mathrm{~h}$ incubations at room temperature. Native soil was not sterilized. Carbazole $(100 \mathrm{mg}$ ) was spiked on $1 \mathrm{~kg}$ of soil as follows. First, carbazole was dissolved in $1 \mathrm{~mL}$ of dichloromethane in a $250 \mathrm{~mL}$ conical flask and the solvent was allowed to vent off. Water $(10 \mathrm{~mL})$ was added to the flask and brought to boiling to desorb the carbazole in the flask. The carbazole suspension in water was then poured on the soil in the metal cup and the soil was mixed thoroughly. Inoculation of the treated soils was carried out after the resuspension of cell pellets in $2.5 \mathrm{~mL}$ of sterile distilled water at a cell concentration of $10^{6} \mathrm{cfu} \mathrm{g}^{-1}$. Uninoculated soils amended with carbazole served as controls. The soil water content was adjusted to $80 \%$ of the water-holding capacity and soil microcosms were incubated in the dark at room temperature $\left(27 \pm 2{ }^{\circ} \mathrm{C}\right)$. Total viable counts (in triplicate) of the microorganisms were determined by plate counts at the beginning and end of the experiment.

\section{Monitoring of substrate depletion}

Residual carbazole was determined at Day 0 and Day 30 by gas chromatography equipped with a flame ionization detector (GC/FID). Extraction was carried out twice, using $20 \mathrm{~mL}$ of dichloromethane as the solvent with $20 \mathrm{~g}$ of soil sample. The sample was then filtered into a glass beaker and the extract was pooled and vented off to approximately $1 \mathrm{~mL}$ to concentrate the analyte (carbazole). The extract was then dispensed in a vial and stored at $4{ }^{\circ} \mathrm{C}$ prior to analysis.

A carbazole standard $(1 \mu \mathrm{L})$ was first injected into the GC/FID to obtain a standard chromatogram, which gave a standard peak area for the carbazole standard. This procedure is carried out to identify the run time and retention time for carbazole prior to injection of the sample analyte. Afterwards, a carbazole dichloromethane extract $(1 \mu \mathrm{L})$ was injected into the GC/FID. The column (OV-3) was $60 \mathrm{~m}$ long. The carrier gas was nitrogen. The injector and detector temperature were maintained at $220{ }^{\circ} \mathrm{C}$ and $250{ }^{\circ} \mathrm{C}$, respectively. The column was programmed at an initial oven temperature of $70^{\circ} \mathrm{C}$ for $2 \mathrm{~min}$, then ramped at $10{ }^{\circ} \mathrm{C} / \mathrm{min}$ to $200{ }^{\circ} \mathrm{C}$ and held for $5 \mathrm{~min}$.

\section{Statistical analysis}

Two-way analysis of variance (ANOVA) was used to ascertain whether the variation between growth observed at
Day 0 and Day 30 was statistically significant. In addition, one-way ANOVA with Tukey's multiple comparison test was used to compare the means within the treatments and ascertain whether they were statistically significant. These tests were conducted using Prism version 5.0 (Graphpad software, San Diego, CA).

\section{Results}

\section{Physico-chemical properties of soil used in the microcosm study}

The physico-chemical properties of the agricultural soil sample are shown in Table 1. The $\mathrm{pH}$ of the soil was close to neutral (6.6), while the moisture content was $9.36 \%$. Grain size determination revealed that the soil was dark grey, clayey, silty sand with a sand content of $89 \%$ and a silt and clay content of $11 \%$. The water-holding capacity of the soil was $40 \%$. The values for total organic carbon, total hydrocarbon, total nitrogen, and available phosphorus and potassium were $1.24 \%, 60.23 \mathrm{mg} / \mathrm{kg}, 0.06 \%$, $3.53 \mathrm{mg} / \mathrm{kg}$ and $2.52 \mathrm{mg} / \mathrm{kg}$, respectively.

\section{Population densities of isolates in soil}

The population densities of the inoculated organisms in sterilized and native (non-sterile) soil microcosms are shown in Figure 2. In the microcosm study with the sterilized soils, strain SL4 had the highest survival rate in the soil, as the initial population density $\left(1.2 \times 10^{7} \mathrm{cfu} / \mathrm{g}\right)$ increased to $1.8 \times 10^{7} \mathrm{cfu} / \mathrm{g}$ after 30 days in the soil. Strain SL1 appeared to have the lowest population density among the three isolates, with a population density of $1.9 \times 10^{6}$ $\mathrm{cfu} / \mathrm{g}$ after 30 days in the soil, a value slightly lower than the initial population. The combination of the three isolates on carbazole revealed a modest increase in population density, from an initial population density of $1.7 \times 10^{7}$ to a final population of $2.1 \times 10^{7} \mathrm{cfu} / \mathrm{g}$. In native soil, there was decrease in population density in all four set-ups compared with the initial populations. However, the autochthonous bacterial

Table 1 - Physico-chemical properties of the soil used in the microcosm study.

\begin{tabular}{lc}
\hline Parameters & Value \\
\hline Moisture (\%) & 9.36 \\
$\mathrm{pH}$ & 6.6 \\
Total organic carbon (\%) & 1.24 \\
Total hydrocarbon content (mg/kg) & 60.23 \\
Total Nitrogen (\%) & 0.06 \\
Available Phosphorus (mg/kg) & 3.53 \\
Potassium (mg/kg) & 2.52 \\
Sand (\%) & 89 \\
Clay and Silt (\%) & 11 \\
Water-holding capacity (\%) & 40 \\
\hline
\end{tabular}




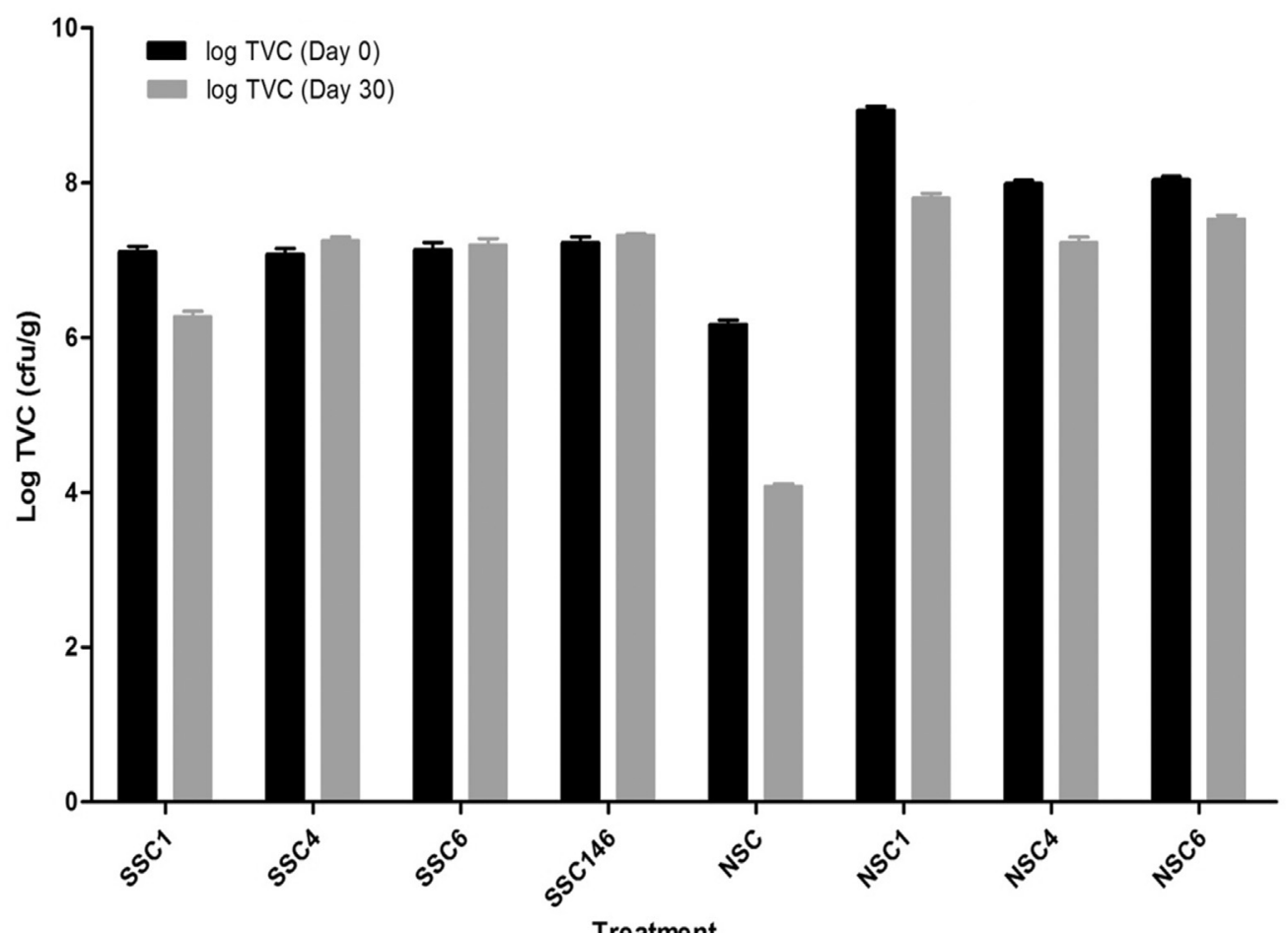

$\mathrm{SSC} 1=$ sterilized soil + carbazole + Achromobacter sp. strain SL1; SSC4 $=$ sterilized soil + carbazole + Pseudomonas sp. strain SL4; SSC6 $=$ sterilized soil + carbazole $+M$. esteraromaticum strain SL6; SSC146= sterilized soil + carbazole + strains SLI, SL4, SL6;
$\mathrm{NSC}=$ native soil + carbazole;

$\mathrm{NSC} 1=$ native soil + carbazole + strain SL1;

$\mathrm{NSC} 4=$ native soil + carbazole + strain SL4;

NSC6 $=$ native soil + carbazole + strain SL6

Figure 2 - Total bacterial populations during the soil microcosm study. The data presented are the mean of triplicate determinations, while error bars represent the standard deviation.

population in the soil had the lowest population density after 30 days of incubation with $100 \mathrm{mg}$ carbazole.

In addition, statistical analysis using two-way ANOVA revealed a significant difference between the population densities at Day 0 and Day 30,with $p<0.0001$, indicating that the difference is highly statistically significant (Table 2).

\section{Degradation of carbazole in soil augmented with bacterial strains}

The percentage degradation of carbazole in the soil microcosm as detected by gas chromatography after extrac- tion with dichloromethane is shown in Figure 3. From the initial carbazole concentration of $100 \mathrm{mg} / \mathrm{kg}$ introduced into the sterile control soil (SSC), $88.12 \mathrm{mg} / \mathrm{kg}$ of carbazole was recovered after 30 days of incubation. In sterilized soil inoculated with strain SL1 (SSC1), out of the initial carbazole concentration of $100 \mathrm{mg} / \mathrm{kg}$ introduced into the soil at day $0,33.04 \mathrm{mg} / \mathrm{kg}$ was recovered after 30 days of incubation, constituting a $33.04 \%$ carbazole recovery, which represents a $66.96 \%$ carbazole removal.

In sterilized soil inoculated with strain SL4 (SSC4), the initial carbazole concentration of $100 \mathrm{mg} / \mathrm{kg}$ was reduced to $17.85 \mathrm{mg} / \mathrm{kg}$ after 30 days of incubation, constitut-

Table 2 - Statistical analysis of the growth patterns of the isolates in the soil microcosm between Day 0 and Day 30.

\begin{tabular}{|c|c|c|c|c|c|c|c|}
\hline Sources of variation & $\begin{array}{l}\text { Degree of } \\
\text { freedom }\end{array}$ & Sum of squares & Mean square & $\mathrm{F}^{* *}$ & $\begin{array}{l}\% \text { of total } \\
\text { variation }\end{array}$ & $\begin{array}{c}\mathrm{p} \text { value } \\
(\mathrm{p}<0.05)\end{array}$ & $\begin{array}{c}\mathrm{p} \text { value } \\
\text { summary }\end{array}$ \\
\hline Interaction & 7 & 4.128 & 0.5897 & 74.91 & $12.46 \%$ & $\mathrm{p}<0.0001$ & $* * *$ \\
\hline Time & 1 & 3.144 & 3.144 & 399.05 & $9.49 \%$ & $\mathrm{p}<0.0001$ & $* * *$ \\
\hline Row factor (treatments) & 7 & 25.73 & 3.676 & 466.9 & $77.67 \%$ & $\mathrm{p}<0.0001$ & $* * *$ \\
\hline Residual & 16 & 0.1260 & 0.007872 & & & & \\
\hline
\end{tabular}

\footnotetext{
*** Highly statistically significant.

** The mean square for each main effect and the interaction effect divided by the within variance.

* Statistically significant.
} 


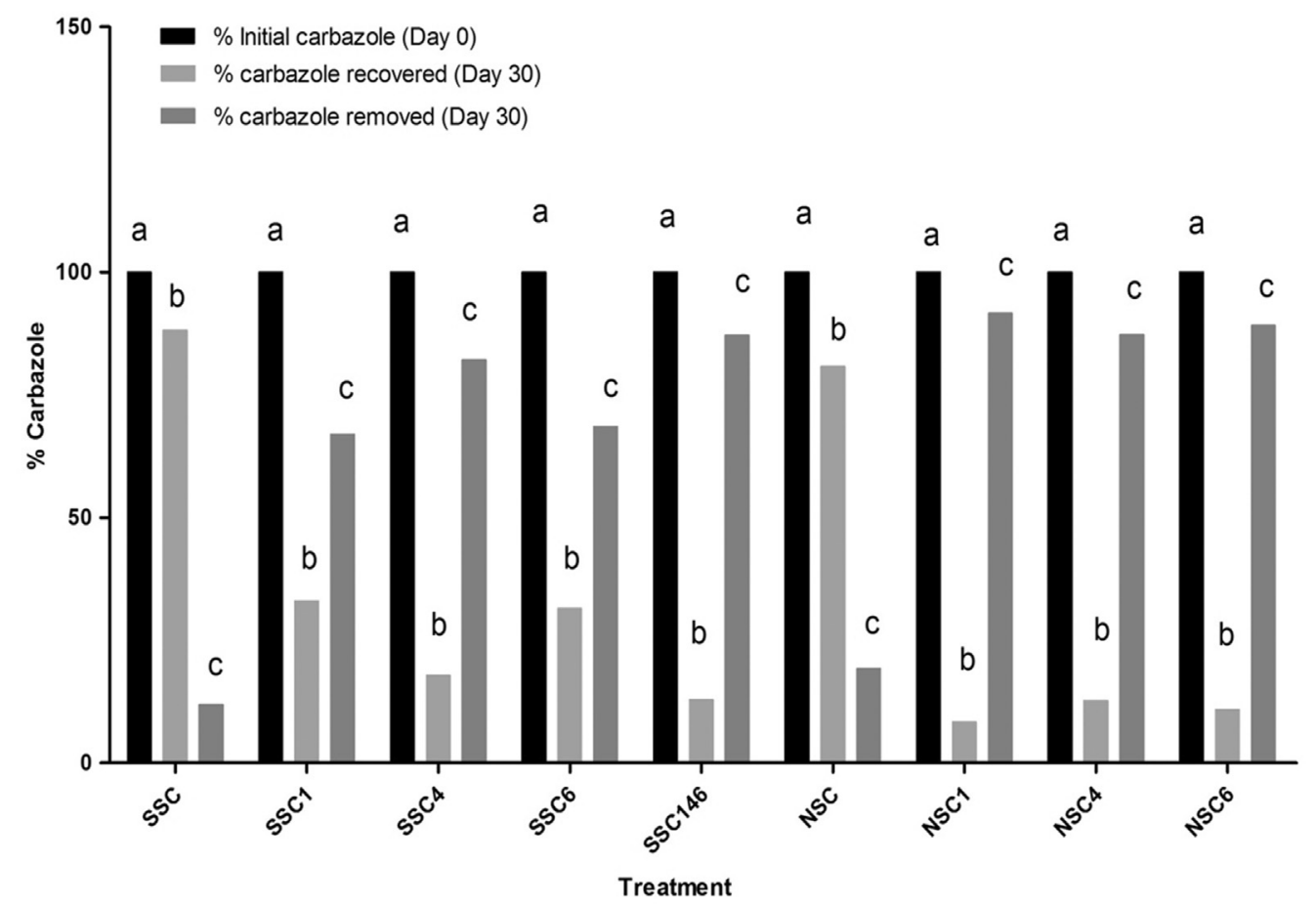

\footnotetext{
$\mathrm{SSC}=$ sterilized soil + carbazole

SSC1 $=$ sterilized soil + carbazole + Achromobacter sp. strain SL1;

$\mathrm{SSC} 4=$ sterilized soil + carbazole + Pseudomonas $\mathrm{sp}$. strain SL4;

SSC6 = sterilized soil + carbazole + M. esteraromaticum strain SL6;

SSC146 $=$ sterilized soil + carbazole + strains SLI, SL4, SL6
}

\begin{abstract}
$\mathrm{NSC}=$ native soil + carbazole;
$\mathrm{NSC} 1=$ native soil + carbazole + strain SL1;

$\mathrm{NSC} 4=$ native soil + carbazole + strain SL4

NSC6 $=$ native soil + carbazole + strain SL6
\end{abstract}

Figure 3 - Percentage of carbazole degraded in sterilized and native soils inoculated with bacterial strains and incubated at room temperature $\left(27 \pm 2{ }^{\circ} \mathrm{C}\right)$ for 30 days.

ing a $17.85 \%$ carbazole recovery, which represents an $82.15 \%$ carbazole removal. Strain SL6 (SSC6) degraded the initial carbazole concentration of $100 \mathrm{mg} / \mathrm{kg}$ at day 0 to $31.46 \mathrm{mg} / \mathrm{kg}$ after 30 days in the soil, constituting a $31.46 \%$ carbazole recovery, which represents a $68.54 \%$ carbazole removal. The combination of the three isolates on carbazole (SSC146) reduced the initial carbazole concentration of $100 \mathrm{mg} / \mathrm{kg}$ at day 0 to $12.87 \mathrm{mg} / \mathrm{kg}$ after 30 days, constituting a $12.87 \%$ carbazole recovery, which represents an $87.13 \%$ carbazole removal.

In the microcosm study with native (non-sterile) soil, from the initial carbazole concentration of $100 \mathrm{mg} / \mathrm{kg}$ introduced into the native soil (NSC), $80.81 \mathrm{mg} / \mathrm{kg}$ of carbazole was recovered after 30 days of incubation, constituting an $80.81 \%$ carbazole recovery, which represents a $19.19 \%$ carbazole removal by indigenous bacteria in the soil.

In native soil inoculated with strain SL1 (NSC1), out of the initial carbazole concentration of $100 \mathrm{mg} / \mathrm{kg}$ introduced into the soil at day $0,8.36 \mathrm{mg} / \mathrm{kg}$ was recovered after 30 days of incubation, constituting an $8.36 \%$ carbazole recovery, which represents a $91.64 \%$ carbazole removal. Strain SL4 (NSC4) degraded the initial carbazole concentration to $12.71 \mathrm{mg} / \mathrm{kg}$ after 30 days of incubation, constituting a $12.71 \%$ carbazole recovery, which represents an
87.29\% carbazole removal. Similarly, strain SL6 (NSC6) degraded the initial carbazole concentration of $100 \mathrm{mg} / \mathrm{kg}$ introduced into the soil at day 0 to $10.87 \mathrm{mg} / \mathrm{kg}$ after 30 days of incubation, constituting a $10.87 \%$ carbazole recovery, which represents an $89.13 \%$ carbazole removal.

In sterilized soil, the rates of carbazole degradation in soil microcosms were $0.093,0.114$ and $0.095 \mathrm{mg} \mathrm{kg}^{-1} \mathrm{~h}^{-1}$ for SL1, SL4 and SL6, respectively. The combination of the three isolates as inoculum in sterilized soil led to a rate of carbazole degradation of $0.121 \mathrm{mg} \mathrm{kg}^{-1} \mathrm{~h}^{-1}$. In native soil, the rate of carbazole degradation by indigenous organisms was $0.027 \mathrm{mg} \mathrm{kg}^{-1} \mathrm{~h}^{-1}$, while $0.127,0.121$ and $0.124 \mathrm{mg} \mathrm{kg}^{-1}$ $\mathrm{h}^{-1}$ were recorded for strains SL1, SL4 and SL6, respectively.

Statistical analysis using one-way ANOVA and Tukey's multiple comparison test also revealed that there is a significant difference between the means of values obtained for the initial carbazole concentration and carbazole recovered/removed from the soil microcosm after 30 days, at a $\mathrm{p}<0.05$ (Table 3 ).

\section{Discussion}

Soil microcosm studies in the laboratory allow for the manipulation of various environmental factors and growth 
Table 3 - Statistical analysis of carbazole concentrations in the soil microcosm between Day 0 and Day 30.

\begin{tabular}{|c|c|c|c|c|}
\hline One- way ANOVA & Sum of squares & Degree of freedom & Mean square & $\mathrm{p}$ value $(\mathrm{p}<0.05)$ \\
\hline Treatment (between columns) & 20260 & 2 & 10130 & \\
\hline Residuals (within columns) & 14940 & 24 & 622.5 & \\
\hline Total & 35200 & 26 & & \\
\hline$F=16.28$ & & & & $\mathrm{p}<0.0001^{* * *}$ \\
\hline Tukey’s Test & Mean Diff. & q & $\mathrm{p}$ value $(\mathrm{p}<0.05)$ & \\
\hline \% Initial carbazole (Day 0) vs. \% carbazole recovered (Day 30) & 67.10 & 8.069 & $* * *$ & \\
\hline \% Initial carbazole (Day 0) vs. \% carbazole removed (Day 30) & 32.90 & 3.956 & $*$ & \\
\hline $\begin{array}{l}\% \text { carbazole recovered (Day 30) vs. \% carbazole removed } \\
\text { (Day 30) }\end{array}$ & -34.20 & 4.113 & $*$ & \\
\hline
\end{tabular}

*** Highly statistically significant.

*Statistically significant.

conditions that could favor the optimal activity of microorganism degradation and facilitate effective biodegradation and bioremediation of polluted soils. The results of such studies could be useful in designing novel bioremediation strategies that may be necessary in reclaiming polluted soil in field conditions.

In a typical soil, inorganic nutrients, especially the macronutrients, are always limited or lacking, resulting in slow pollutant degradation even in the presence of the carbon and energy required for growth (Giordani et al., 1998; Vidali, 2001). For instance, the concentration of nitrogen $(0.06 \%)$ and phosphorus $(3.53 \mathrm{mg} / \mathrm{kg})$ at the sampling site is very low, which may be due to their high demand by microorganisms for sugar phosphorylation, synthesis of amino acids, nucleic acids, nucleotides, and other cellular processes (Andrew and Jackson, 1996).

Bioaugmentation (seeding) is the introduction of strains with desired degradative capabilities against the target pollutants, either with or without nutrients, into the contaminated environment to augment the indigenous microbial population (Andreoni and Gianfreda, 2007). In this study, the three strains SL1, SL4 and SL6 were still detectable after 30 days of inoculation in both sterilized soil and native soil at very high concentrations $\left(>10^{6} \mathrm{cfu} / \mathrm{g}\right)$. In addition, with the exception of SSC4, higher population counts were recovered from the native soil than from the sterilized soil. This indicates that there is a positive interaction between the seeded strains and the autochthonous organisms in the soil, which enhances their survival and ability to compete favorably with the indigenous microbial community.

Statistical analysis indicates that while time accounted for $9.49 \%$ of the total variance, treatments (row factor) accounted for $77.67 \%$ of the total variance observed between the population densities at Day 0 and Day 30. This is not surprising, as the physiological properties and carbazole degradation competence of each of the seeded strains played a prominent role in their survival and proliferation in soil. This may explain why Pseudomonas sp. strain SL4 and M. esteraromaticum strain SL6, which belong to classes of microorganisms reputed to possess a remarkable degree of physiological and genetic adaptability and an unrivalled capability to degrade recalcitrant pollutants and to survive in harsh environments (Vankateswaran et al., 1995; Nojiri et al., 1999; Larkin et al., 2005; Mutnuri et al., 2005; Kanaly and Harayama, 2010), survived better in the soil than Achromobacter sp. strain SL1, due to the oligotrophic nature of the soil used. Moreover, statistical analyses also indicated that the difference between the population densities at Day 0 and Day 30 was highly statistically significant $(\mathrm{p}<0.0001)$.

In sterilized control soil (SSC), out of the $100 \mathrm{mg} / \mathrm{kg}$ carbazole introduced into the soil, $88.12 \mathrm{mg} / \mathrm{kg}$ was recovered after 30 days of incubation. This may be attributed to the sequestration of carbazole into soil pores and loss during extraction (Kastner et al., 1998).

Statistical analysis using one-way ANOVA and Tukey's multiple comparison test showed that the mean difference between the initial carbazole concentration (Day 0 ) and carbazole recovered after 30 days was highly statistically significant $(\mathrm{p}<0.0001)$. This indicates the importance of bioremediation (bioaugmentation) in the removal of hydrocarbon pollutants from environmental compartments.

In sterilized soil amended with carbazole and isolates, Pseudomonas sp. strain SL4 (SSC4) removed the highest concentration of carbazole $(82.15 \mathrm{mg} / \mathrm{kg} ; 82.15 \%)$. In a previous study of CFMM amended with carbazole, this isolate also degraded the highest percentage of carbazole (85\%; Salam et al., 2014). The fact that this isolate maintained a high carbazole degradative ability in liquid culture and in soil suggests the stability of its carbazole degradation genes and makes it a potential candidate for bioremediation of environments impacted by carbazole and related compounds. 
In this study, the percentage of carbazole removed in native soil (non-sterile soil) in the presence of each of the three strains is higher (NSC1 91.64\%, NSC4 87.29\%, NSC6 $89.13 \%$ ) than the percentage of carbazole removed by the three strains in sterilized soil (SSC1 66.96\%, SSC4 $82.16 \%$, SSC6 68.54\%). This increase may be due to positive interactions between the autochthonous and seeded bacterial strains, which results in higher carbazole degradation rates. In addition, agricultural practices, such as pesticide or herbicide application, may result in the acquisition of some catabolic genes by the autochthonous bacteria, which perhaps allowed them a relative ability to degrade carbazole (19.19\%). Moreover, the physico-chemical analysis of the soil indicated the presence of hydrocarbon $(60.23 \mathrm{mg} / \mathrm{kg})$, which perhaps lends some of the autochthonous bacteria a relative ability to degrade carbazole. Furthermore, sterilization of soil may have altered or denatured certain factors for the stimulation of biomass increase and utilization (Obayori et al., 2013).

The percentage of carbazole removed by the consortium of the three bacterial strains (SSC146, 87.13\%) is higher than the percentage removed by each strain individually (SSC1 66.96\%, SSC4 82.16\%, SSC6 68.54\%) in sterilized soil. This was expected, as previous reports have indicated that mixed cultures exhibit superior degradative competence than do pure culture strains (Leahy and Colwell, 1990; Adebusoye et al., 2007).

Aside from their ability to compete favorably with the autochthonous organisms in the soil, the strongest factor for the survival of the seeded strains may be their ability to detect and utilize the introduced carbazole as a source of carbon and energy, as reflected by the reduction of this $\mathrm{N}$-heterocyclic compound over a period of 30 days. These results further corroborate, as suggested in previous reports, the necessity of bioaugmentation and other bioremediation techniques in expediting the biodegradation of hydrocarbon pollutants, provided that the necessary conditions such as inoculum size and inoculation protocol are designed to permit the growth and activity of the seeded organisms (Grosser et al., 1991; Vidali, 2001; Fava et al., 2004).

\section{References}

Adebusoye SA, Ilori MO, Amund OO et al. (2007) Microbial degradation of petroleum in a polluted tropical stream. World $\mathrm{J}$ Microbiol Biotechnol 23:1149-1159.

Andreoni V, Gianfreda L (2007) Bioremediation and monitoring of aromatic-polluted habitats. Appl Microbiol Biotechnol 76:287-308.

Andrew RWJ, Jackson JM (1996) Pollution and waste management. In: The natural environment and human impact. Longman Publishers, Singapore, pp 281-297.

Blum P, Sagner A, Tiehm A et al. (2011) Importance of heterocyclic aromatic compounds in monitored natural attenuation for coal tar contaminated aquifers: a review. J Contam Hydrol 126:181-194.
Day PR (1965) Particle fractionation and particle-size analysis. In Methods of Soil Analysis, part 1. (C.A. Black et al ed.) American Soc. of Agronomy Inc., Madison, pp. 545-567.

Fava F, Berselli S, Conte P et al. (2004) Effects of humic acid substances and soya lecithin on the aerobic bioremediation of soil historically contaminated by polycyclic aromatic hydrocarbons (PAHs). Biotech Bioeng 88:214-223.

Giordani G, Donnelly A, Azzoni R (1998) The uptake of inorganic phosphate by $Z$. noltii in the Basin d'Arcachon. In: Proceedings (Handbook) of Summer Conference of the Society for Applied Microbiology. University of Lancaster, Lancaster, pp. 22-23.

Grosser RJ, Warshawsky D, Vestal JR (1991) Indigenous and enhanced mineralization of pyrene, benzo(a)pyrene and carbazole in soils. Appl Environ Microbiol 57:3462-3469.

Habe H, Chung JS, Lee JH et al. (2001) Degradation of chlorinated dibenzofurans and dibenzo-p-dioxins by two types of bacteria having angular dioxygenases with different features. Appl Environ Microbiol 67:3610-3617.

Johansen SS, Hansen AB, Mosbaek H et al. (1997) Identification of heteroaromatic and other organic compounds in ground water at creosote-contaminated sites in Denmark. Groundwater Monit Rem 17:106-115.

Johnsen AR, Wick LY, Harms H (2005) Principles of microbial PAH-degradation in soil. Environ Poll 133:71-84.

Jones MD, Singleton DR, Carstensen DP et al. (2008) Effect of incubation conditions on the enrichment of pyrene-degrading bacteria identified by stable-isotope probing in an aged, PAH-contaminated soil. Microbial Ecol 56:341-349.

Kanaly RA, Harayama S (2010) Advances in the field of high molecular-weight polycyclic aromatic hydrocarbon biodegradation by bacteria. Microbiol Biotechnol 3:132-164.

Kastner M, Breuer-Jammali M, Mahro B (1998) Impact of inoculation protocols, salinity, and $\mathrm{pH}$ on the degradation of polycyclic aromatic hydrocarbons (PAHs) and survival of PAH-degrading bacteria introduced into soil. Appl Environ Microbiol 64:359-362.

Larkin MJ, Kulakov LA, Allen CC (2005) Biodegradation and Rhodococcus- masters of catabolic versatility. Curr Opin Biotechnol 16:282-290.

Leahy JG, Colwell RR (1990) Microbial degradation of hydrocarbons in the environment. Microbiol Rev 54:305-315.

Lide DR (2003) Handbook of Chemistry and Physics. $84^{\text {th }}$ Edition. CRC Press, Boca Raton.

Mutnuri S, Vasudevan N, Kaestner M (2005) Degradation of anthracene and pyrene supplied by microcrystals and nonaqueous-phase liquids. Appl Microbiol Biotechnol 67:569576.

Nojiri H, Nam JW, Kosaka M et al. (1999) Diverse oxygenations catalyzed by carbazole 1,9a-dioxygenase from Pseudomonas sp. strain CA10. J Bacteriol 181:3105-3113.

Nojiri H, Omori T (2007) Carbazole metabolism by Pseudomonads. In: Ramos JL, Filloux A. (eds) Pseudomonas. Springer, New York, pp. 107-145.

Obayori OS, Ilori MO, Amund OO (2013) Degradation of spiked pyrene and non-pyrene hydrocarbons in soil microcosms by Pseudomonas species isolated from petroleum polluted soils. Petrol Sci Technol 31:1674-1680.

Peddinghaus S, Brinkmann M, Bluhm K et al. (2012) Quantitative assessment of the embryotoxic potential of NSO- 
heterocyclic compounds using zebrafish (Danio rerio). Reproduc Toxicol 33:224-232.

Reid BJ, Jones KC, Semple KT (2000) Bioavailability of persistent organic contaminants in soils and sediments- a perspective on mechanisms, consequences and assessment. Environ Pollut 108:103-112.

Salam LB, Ilori MO, Amund OO et al. (2014) Carbazole angular dioxygenation and mineralization by bacteria isolated from hydrocarbon-contaminated tropical African soil. Environ Sci Pollut Res 21:9311-9324.

Smith CJ, Hansch C (2000) The relative toxicity of compounds in mainstream cigarette smoke condensate. Food Chem Toxicol 38:637-646.

Vankateswaran K, Hoaki T, Kato M et al. (1995) Microbial degradation of resins fractionated for Arabian light crude oil. Can J Microbiol 41:418-424.
Vidali M (2001) Bioremediation. An overview. Pure Appl Chem 73:1163-1172.

Vinas M, Sabate J, Espuny MJ et al. (2005) Bacterial community dynamics and polycyclic aromatic hydrocarbon degradation during bioremediation of heavily creosote contaminated soil. Appl Environ Microbiol 71:7008-7018.

Watanabe K, Teramoto M, Futamata H et al. (1998) Molecular detection, isolation, and physiological characterization of functionally dominant phenol-degrading bacteria in activated sludge. Appl Environ Microbiol 64:4396-4402.

Widada J, Nojiri H, Yoshida T et al. (2002) Enhanced degradation of carbazole and 2,3-dichlorodibenzo-p-dioxin in soils by Pseudomonas resinovorans strain CA10. Chemosphere 49: 485-491.

Associate Editor: Fernando Dini Andreote

All the content of the journal, except where otherwise noted, is licensed under a Creative Commons License CC BY-NC. 